\title{
A Prospective Randomized Comparison of CT and MRI Pre-operative Localization for Pallidotomy
}

\author{
Christopher R. Honey and Robert A. Nugent
}

\begin{abstract}
Objective: During the pallidotomy procedure, is pre-operative localization with MRI more accurate than CT and does it result in a significant difference in surgical outcome? Methods: Twenty-four Parkinson's Disease patients received a unilateral pallidotomy for their motor symptoms. Dyskinesia was scored pre- and six weeks postoperatively. All patients had a pre-operative CT scan and MRI to calculate the target co-ordinates. Patients were then randomly selected to proceed with either the CT or MRI coordinates. The final position for the lesion was determined with intraoperative macrostimulation and impedance measurements. The percentage improvement of dyskinesia was noted for each patient and the two groups compared by the Mann-Whitney test. The distance from the final target to the MRI and CT pre-operative co-ordinates were calculated for each patient. The mean distance for each modality was then compared by Student's t-test. The number of electrode repositionings was also recorded for each patient and the two groups compared by the nonparametric Mann-Whitney test. Results: Although the MRI co-ordinates were significantly ( $p<0.023)$ closer to the final target, this did not translate into a significant reduction in electrode repositionings. There was no significant difference in the improvement in dyskinesia between the two groups. Conclusions: The pre-operative MRI co-ordinates were significantly ( $\mathrm{p}=0.023$ ) closer to the final target than those from the CT. The potential advantages and disadvantages of both imaging modalities are reviewed. There was no significant difference in surgical outcome using either MRI or CT for pre-operative localization in pallidotomy.
\end{abstract}

RÉSUMÉ: Une comparaison randomisée prospective de la localisation préopératoire par CT scan et RMN de la pallidotomie. Objectif: Pendant la pallidotomie, la localisation préopératoire par RMN est-elle plus précise que par CT scan et la méthode de localisation a-t-elle un impact significatif sur le résultat de la chirurgie? Méthodes: Vingt-quatre patients atteints de la maladie de Parkinson ont subi une pallidotomie unilatérale dont l'indication était des symptômes moteurs. La dyskinésie a été évaluée avant et six semaines après l'intervention. Tous les patients ont eu un CT scan et une RMN préopératoire pour calculer les coordonnées de la cible. On a ensuite sélectionné au hasard les patients dont on utiliserait les coordonnées obtenues par l'une ou l'autre méthode au moment de la chirurgie. La position finale de la lésion a été déterminée par macrostimulation peropératoire et par des mesures d'impédance. Le pourcentage d'amélioration de la dyskinésie a été noté pour chaque patient et les deux groupes ont été comparés par le test de Mann-Whitney. La distance de la cible finale aux coordonnées préopératoires obtenues par RMN et CT scan a été calculée pour chaque patient. La distance moyenne pour chaque méthode a ensuite été comparée au moyen d'un test de t de Student. Le nombre de repositionnements des électrodes a également été noté pour chaque patient et comparé entre les deux groupes au moyen du test non paramétrique de Mann-Whitney. Résultats: Bien que les coordonnées obtenues par RMN aient été significativement plus rapprochées $(\mathrm{p}<0.023)$ de la cible finale, ceci ne s'est pas traduit par une réduction significative du nombre de repositionnements des électrodes. Il n'y avait pas de différence significative dans l'amélioration des dyskinésies entre les deux groupes. Conclusions: Les coordonnées préopératoires obtenues par RMN étaient significativement plus près $(\mathrm{p}<0.023)$ de la cible finale que celle obtenues par CT scan. Les avantages et les désavantages possibles des deux méthodes d'imagerie sont revues. Il n'y avait pas de différence significative dans le résultat chirurgical quand l'une ou l'autre méthode de localisation avait été utilisée avant la pallidotomie.

Can. J. Neurol. Sci. 2000; 27: 236-240

The pallidotomy procedure has enjoyed a resurgence in popularity since Laitinen published his influential paper in 1992. ${ }^{1}$ Despite the large number of patients being operated upon, there is a striking variation in the techniques utilized to perform this procedure. Perhaps more disconcerting are the assertions of some centres that their techniques are superior despite any prospective comparisons. In an effort to bring evidenced based medicine into this sometimes dogmatic field, we begin by analysing one variation of the surgical technique - pre-operative target localization. Some centres use a CT $\operatorname{scan}^{2,3}$ while others use a $\mathrm{MRI}^{4-9}$ or a combination of both. ${ }^{10,11} \mathrm{~A}$ few centres continue to use ventriculography. ${ }^{12}$ The accuracy of CT and MRI have been directly compared for small cohorts with brain lesions ${ }^{13}$ or deep brain electrodes ${ }^{3}$ and in a group receiving a mixture of stereotaxic procedures. ${ }^{14}$ There is no information, however, on whether functional stereotaxic surgery utilizing CT or MRI leads to i) improved clinical outcome or ii) fewer

From the Division of Neurosurgery, Department of Radiology, University of British Columbia, Vancouver, BC, Canada

ReCEIVED JANUARY 3, 1999. ACCEPTED IN FINAL FORM APRIL 26, 2000. Reprint requests to: C.R. Honey, Suite 310A, 700 West 10th Avenue, Vancouver, BC Canada V5Z 4E5 


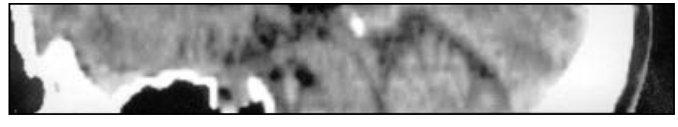

Figure 1: A typical CT scan from the series. Left: the sagittal reformat; Centre: an axial image at the level of the intercommissural line, and Right: an axial image at the level of the target (4 $\mathrm{mm}$ below centre). On the sagittal reformat, the length and direction of the intercommissural line is difficult to interpret because the anterior commissure is particularly difficult to see. On the axial image, the edge of the internal capsule (slightly hypodense) is difficult to delineate from the pallidum.
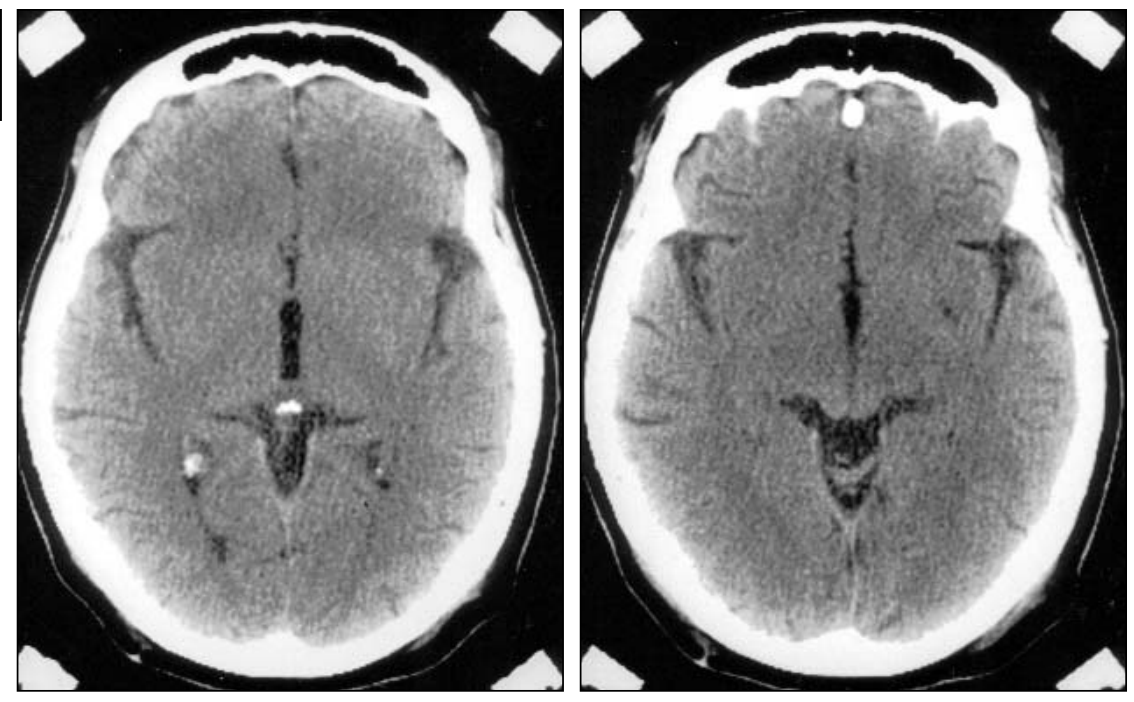

intraoperative electrode repositionings. We postulated that the MRI's superior imaging of i) the internal capsule (allowing more precise pre-operative targeting in the axial plane) and ii) intercommissural line (allowing more precise vertical slice selection) would result in more accurate pre-operative localization than CT. This paper prospectively studies these factors in a cohort of Parkinsonian patients receiving a unilateral ventroposterior pallidotomy.

\section{METHODS AND MATERIALS}

\section{Patients}

Twenty-four consecutive Parkinson's Disease (PD) patients were entered into this study. Patients were selected for unilateral pallidotomy based on their motor symptoms (medically intractable dyskinesia \pm severe bradykinesia and tremor). Patients were brought into hospital the evening before surgery and all Parkinsonian medications stopped at midnight. The morning of surgery, patients had a Universal Compact Head Ring (Radionics Inc.) attached to their skull under local anaesthesia.

\section{CT Scan}

All scans were performed on a HiSpeed CT/ $\mathrm{i}^{\mathrm{TM}}$ scanner (GE Medical Systems) using Version 5.0 software. Axial cuts $3 \mathrm{~mm}$ thick every $2 \mathrm{~mm}$ (i.e. overlapping) were made through the basal ganglia with a CRW localizer frame (Radionics Inc.). Images were reformatted sagittally to measure the intercommissural line, note its angulation with horizontal and to locate the posterior commissure relative to the pineal calcification. The target was
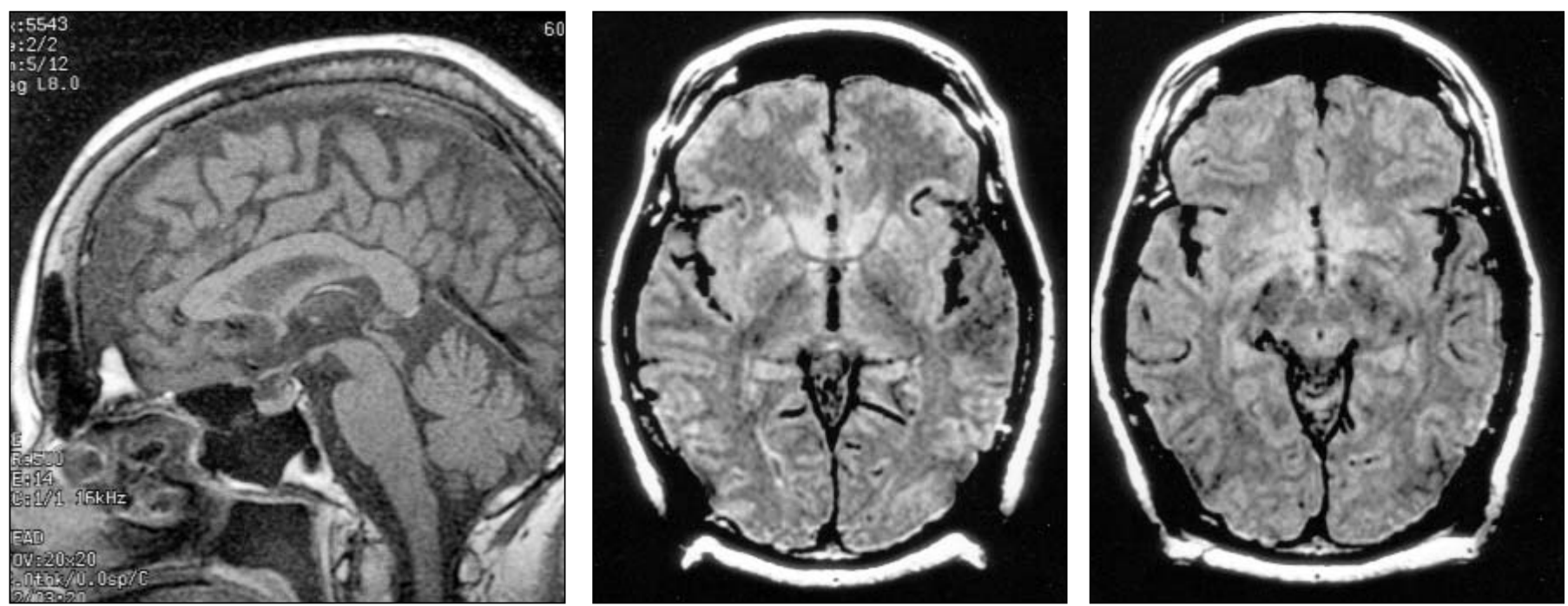

Figure 2: The MRI of the same patient in Figure 1. Left: the mid-sagittal image; Centre: an axial image at the level of the intercommissural line, and Right: an axial image at the level of the target $(4.4 \mathrm{~mm}$ below centre). The anterior commissure (bulging posteriorly from the anterior wall of the third ventricle) and posterior commissure (bulging anteriorly from the posterior wall of the third ventricle immediately above the aqueduct) are immediately obvious on the sagittal image making measurements of the intercommissural line easier than from the CT. The boundary between the internal capsule (low signal) and pallidum (higher signal) is far clearer than the corresponding CT image. 
selected $2 \mathrm{~mm}$ anterior, $19-23 \mathrm{~mm}$ lateral (just lateral to the internal capsule), and 4-6 mm below the mid-commissural point. An example is shown in Figure 1.

\section{MRI}

All scans were performed on a Signa Advantage 1.5T scanner (GE Medical Systems) with Platform 5.7 software. Using a Universal Compact Localizer Frame (Radionics Inc.), a sagittal T1-weighted scan $(2 \mathrm{~mm}$ thick no gap, TR=500 ms, TE=14 ms, $\mathrm{FOV}=28 \mathrm{~cm}$, matrix 256x192, NEX=2, frequency direction = superior to inferior, with no phase wrap and a saturation band inferiorly, time $=3: 20$ ) was performed first. The intercommissural line was measured and its angulation away from horizontal noted. The vertical position of the optic tract was also documented. Axial fast spin echo proton density scans $(2.2 \mathrm{~mm}$ thick with no gap, TR=2000 ms, TE=32 ms, echo train length=6, matrix 256x256, $\mathrm{NEX}=3$, frequency direction $=$ anterior to posterior, using flow compensation, no phase wrap and a saturation band inferiorly, time $=4: 22 \mathrm{~s}$ ) were then done through the basal ganglia. The target was selected $2 \mathrm{~mm}$ anterior, 19-23 $\mathrm{mm}$ lateral, and 2.2-6.6 mm below the mid-commissural point. The lateral position was selected to place the target abutting the internal capsule (in the ventromedial portion of pallidum). The vertical position was selected on the lowest cut through the basal ganglia (above the ambient cistern). An example is shown in Figure 2.

\section{Surgery}

Each patient was randomly assigned to proceed with either the CT or MRI co-ordinates. Patients were taken to the operating theatre and given pre-operative antibiotics (cefazolin 1g I.V.). The procedures were performed under local anaesthesia $(0.25 \%$ Marcaine without epinephrine) without systemic sedation. A burr hole was placed to allow the stimulating electrode $(1.5 \mathrm{~mm}$ exposed tip, $1.8 \mathrm{~mm}$ diameter) (Radionics Inc.) to approach the pallidum in a parasagittal plane $65^{\circ}$ up from the intercommisural line. Impedance measurements and responses to macrostimulation were made every $2 \mathrm{~mm}$ beginning $10 \mathrm{~mm}$ above the target. Macrostimulation with $1 \mathrm{~ms}$ square wave pulses at $2 \mathrm{~Hz}$ for motor and at $50 \mathrm{~Hz}$ and $100 \mathrm{~Hz}$ for sensory responses were performed with a RFG-3C Lesion Generator (Radionics Inc.). The electrode was moved i) laterally $2 \mathrm{~mm}$ if motor $(2 \mathrm{~Hz})$ or sensory $(50 \mathrm{~Hz})$ responses were recorded below 2.5 volts (a second move $2 \mathrm{~mm}$ anteriorly was occasionally needed), ii) medially $2 \mathrm{~mm}$ if no sensory responses were recorded at 5.0 volts $(50 \mathrm{~Hz})$ or 3.0 volts $(100 \mathrm{~Hz})$, iii) vertically $2 \mathrm{~mm}$ if visual phosphemes were reported at $100 \mathrm{~Hz}$ below 3.0 volts. Lesions were made at $80^{\circ} \mathrm{C}$ for 60 seconds at the target and at $3 \mathrm{~mm}$ and $6 \mathrm{~mm}$ above the target. Patients were observed overnight and discharged in the morning.

\section{Analysis}

Patient's dyskinesia was scored pre-operatively and six weeks postoperatively using the rating scale of Goetz. ${ }^{15}$ The percentage improvement was noted for each patient and the two groups compared by the Mann-Whitney test. The distance from the final target to the MRI and CT pre-operative co-ordinates were calculated for each patient. The distance was calculated using the $\mathrm{x}, \mathrm{y}$, and $\mathrm{z}$ co-ordinates of the pre-operative sites and the final target determined intraoperatively. The mean distance for each modality was then compared by Student's t-test. The number of electrode repositionings was also recorded for each patient and the two groups compared by the nonparametric Mann-Whitney test. Analyses were performed using SYSTAT software Version 8.0 (SPSS Inc.).

\section{Results}

Detailed postoperative motor scores for similar cohorts have been published previously by our centre. ${ }^{16,17}$ There was no significant difference in the postoperative improvement of dyskinesia scores between the patients where CT $(n=12)$ or MRI $(\mathrm{n}=12)$ co-ordinates were utilized. Dyskinesia was reduced by a mean ( \pm standard deviation) of $79 \pm 17 \%$ and $84 \pm 15 \%$ respectively in the two groups. The mean distance $( \pm$ standard deviation) from the pre-operative co-ordinates to the final target were $3.7 \pm 1.1 \mathrm{~mm}$ for CT and $2.3 \pm 1.6 \mathrm{~mm}$ for MRI. The MRI calculation was significantly closer to the final target $(\mathrm{p}=0.023)$. More patients in the MRI group (7/12) than the CT group (3/12) did not require an electrode repositioning. Although there was a trend for the group utilizing MRI co-ordinates to have fewer electrode repositions per operation $(0.75 \pm 0.96)$ than the group utilizing CT co-ordinates $(1.2 \pm 0.87)$, this did not reach statistical significance at the 0.05 level.

\section{Discussion}

Ventriculography was the gold standard for pallidal targeting for many decades. It was hindered by the possibility of parallax errors, distortion of the third ventricle's shape, and the uncertain anatomical correlation between ventricular anatomy and paraventricular targets. ${ }^{18,19}$ Although it is still used, ${ }^{12}$ most centres avoid it because of the associated morbidity. ${ }^{20,21}$

Following Brown's ${ }^{22}$ description of CT guided stereotaxy, neurosurgeons began to utilize this technique. It was reported to be as accurate as ventriculography. ${ }^{23}$ Laitinen's ${ }^{1}$ sentinel paper used CT for pre-operative localization. There has been a recent trend for stereotaxic neurosurgeons to utilize MRI scans to localize the pallidum. ${ }^{4-9}$ The potential benefits of MRI include enhanced anatomic detail, easier visualization of the intercommissural line in the sagittal plane, and better grey-white differentiation. It also has the potential to directly visualize the pallidum without estimating its position from the intercommissural line. ${ }^{10,24}$ Potential problems include image distortion, long scanning times (blurred pictures if the patient moves), claustrophobia, and the standard contraindications for MRI. Many excellent centres continue to utilize CT scans. ${ }^{2,25}$ The potential benefits of CT include faster scan times, less expensive equipment, and no distortion of images. Its disadvantage is poorer anatomic detail (including grey-white differentiation). Some centres have combined the two techniques. ${ }^{10,11}$

There are two main sources of distortion for MRI: gradient field nonlinearities and resonance offsets. The three mutually orthogonal gradient coils are designed to produce linear gradients. Imperfections can occur resulting in distortions that are maximal at the edge of the MRI slice. ${ }^{26}$ Since the pallidotomy target is very near the centre of the slice, these distortions are minimized. With a field of view of $28 \mathrm{~cm}$, the fiducial markers will also lie within the area of gradient linearity 
guaranteed by the manufacturer. Resonance offsets are due to chemical shifts and magnetic field inhomogeneities. Chemical shifts due to the different gyromagnetic ratio of the hydrogen atoms in fat or water can cause objects (made of fat or water) to appear to shift different distances along the gradient field. The fiducial markers (aqueous solution of cupric sulphate) were chosen to match the gyromagnetic ratio of hydrogen atoms in the pallidotomy target (i.e. water not fat). Magnetic field inhomogeneities are produced by the scanner (less of a problem with more modern magnets) and by the object being imaged (susceptibility artefacts). If the object being imaged has a magnetic dipole (e.g. hydrogen atom) it will affect the main magnetic field. How much it disturbs the field is called its magnetic susceptibility. When objects of different susceptibility (e.g. air-water or air-fat) are close together, geometric distortion can occur near the interface. The tissues near the pallidotomy target are uniform and thus not prone to this distortion but the fiducial markers do have a water-air interface. ${ }^{27}$ This effect occurs only in the read-out gradient direction (not the phase encoding direction). ${ }^{26}$ In our study, this would affect the $y$ (anteroposterior) co-ordinate. Inspection of the fiducial images did not reveal obvious distortion (e.g. oval rather than round shape).

The difference in stereotaxic localization between CT and MRI has been well-documented. ${ }^{13,14,28,29}$ Targets visualized with the two techniques have been reported to vary by $3-5 \mathrm{~mm}$ or to be insignificantly different. ${ }^{14,28}$ In our cohort of patients $(n=24)$, there was no significant difference in clinical outcome between the groups using CT or MRI co-ordinates. This was not surprising since the method of final target selection (intraoperative electrophysiology) and lesioning were identical for the two groups. Our postulate that the MRI's superior imaging of the internal capsule and intercommissural line would result in more accurate target selection was confirmed. The MRI co-ordinates were statistically closer to the final target $(p=0.023)$ than those generated from the CT. This probably reflects the improved visualization of the internal capsule when selecting the lateral coordinate for the target with MRI compared to CT. Although the MRI group had double the percentage of 'direct hits' (i.e. no need for electrode repositioning) compared to the CT group, this did not translate into a significantly reduced number of electrode repositionings. It is likely that our sample size was too small to detect this difference. In order to prove this increased percentage was statistically significant, one would need 116 patients (assuming an increase from $25 \%$ to $50 \%$ using a two-sided $\alpha=0.05$ and a power $=0.80$ ).

We conclude that i) MRI offers more accurate pre-operative localization of the pallidotomy target than $\mathrm{CT}$, and ii) there is no significant difference in the reduction of dyskinesia following pallidotomy performed with either CT or MRI pre-operative localization. The trend for fewer electrode repositionings using MRI has led our centre to switch from CT to MRI for the preoperative stereotaxic localization of pallidotomies. There is a small but real risk of hemorrhage with each electrode pass through the brain. Although there were no complications in this cohort, with larger numbers of patients over the course of a year, we hope the reduced number of electrode passes will translate into reduced complications.

\section{ACKNOWLEDGEMENT}

The authors thank the Division of Neurosurgery for their support and Dr. Alex MacKay for his review of the manuscript.

\section{REFERENCES}

1. Laitinen LV, Bergenheim AT, Hariz, et al. Leksell's posteroventral pallidotomy in the treatment of Parkinson's disease. J Neurosurg 1992; 76: 53-61.

2. Samuel M, Caputo E, Schrag A, et al. A study of medial pallidotomy for Parkinson's disease: clinical outcome, MRI location and complications. Brain 1998; 121: 59-75.

3. Smith JR, Hardy TL, Rose DF, et al. Comparison of CT- versus MRI-guided, computer assisted depth electrode implantation. Stereotact Funct Neurosurg 1992; 58: 189-193.

4. Cohn MC, Hudgins PA, Sheppard SK, et al. Pre- and postoperative MR evaluation of stereotactic pallidotomy. Am J Neurorad 1998; 19: $1075-1080$.

5. Desaloms JM, Krauss JK, Lai EC, et al. Posteroventral medial pallidotomy for treatment of Parkinson's disease: pre-operative magnetic resonance imaging features and clinical outcome. $\mathbf{J}$ Neurosurg 1998; 89: 194-199.

6. Favre J, Taha JM, Nguyen TT, et al. Pallidotomy: a survey of current practice in North America. Neurosurgery 1996; 39: 883-890.

7. Kondziolka D, Bonaroti E, Baser S, et al. Outcomes after stereotactically guided pallidotomy for advanced Parkinson's disease. J Neurosurg 1999; 90: 197-202.

8. Lang AE, Lozano AM, Montgomery E, et al. Posteroventral medial pallidotomy in advanced Parkinson's disease. N Engl J Med 1997; 337: 1036-1042.

9. Vitek JL, Bakay RAE, Hashimoto T, et al. Microelectrode-guided pallidotomy: technical approach and its application in medically intractable Parkinson's disease. J Neurosurg 1998; 88: 1027-1043.

10. Giller CA, Dewey RB, Ginsburg MI, et al. Stereotactic pallidotomy and thalamotomy using individual variations of anatomic landmarks for localization. Neurosurgery 1998; 42: 56-62.

11. Heilbrun MP, Koehler S, McDonald P, et al. Optimal target localization for ventroposterolateral pallidotomy: the role of imaging, impedance measurement, macrostimulation and microelectrode recording. Stereotact Funct Neurosurg 1997; 69: 19-27.

12. Mandybur G, Morenski J, Kuniyoshi S, et al. Comparison of MRI and ventriculographic target acquisition for posteroventral pallidotomy. Stereotact Funct Neurosurg 1995; 65: 54-59.

13. Gerdes JS, Hitchon PW, Neerangun W, et al. Computed tomography versus magnetic resonance imaging in stereotactic localization. Stereotact Funct Neurosurg 1994; 63: 124-129.

14. Kondziolka D, Dempsey PK, Lunsford LD, et al. A comparison between magnetic resonance imaging and computed tomography for stereotactic coordinate determination. Neurosurgery 1992; 30: 402-406.

15. Goetz CG, Stebbins GT, Shale HM, et al. Utility of an objective dyskinesia rating scale for Parkinson's disease: inter- and intrarater reliability assessment. Mov Disord 1994; 9: 390-394.

16. Honey CR, Stoessl AJ, Tsui JKC, et al. Unilateral pallidotomy for reduction of parkinsonian pain. J Neurosurg 1999; 91: 198-201.

17. Kishore A, Turnbull IM, Snow BJ, et al. Efficacy, stability and predictors of outcome of pallidotomy for Parkinson's disease: six month follow-up with additional 1-year observations. Brain 1997; 120: 729-737.

18. Hariz MI, Bergenheim AT, Fodstad H. Air-ventriculography provokes an anterior displacement of the third ventricle during functional stereotaxic procedures. Acta Neurochir (Wien) 1993; 123: $147-152$.

19. Kawashima Y, Chen HJ, Takahashi A. Application of magnetic resonance imaging in functional stereotactic thalamotomy for the evaluation of individual variations of the thalamus. Stereotact Funct Neurosurg 1992; 58: 33-38.

20. Alterman RL, Kall BA, Cohen H, et al. Stereotactic ventrolateral thalamotomy: is ventriculography necessary? Neurosurgery 1995; 37: 717-722. 
21. Kelly PJ. Contemporary stereotactic ventralis lateral thalamotomy in the treatment of Parkinsonian tremor and other movement disorders. In: Heilbrun MP (Ed). Stereotactic Neurosurgery. Baltimore, Williams \& Wilkins, 1988, 133-148.

22. Brown RA. Computerized tomography-computer graphics approach to stereotactic localization. J Neurosurg 1979; 50: 715-720.

23. Tasker RR, Dostrovsky JO, Dolan EJ. Computerized tomography (CT) is just as accurate as ventriculography for functional stereotactic thalamotomy. Stereotact Funct Neurosurg 1991; 57: 157-166.

24. Patil A-A, Hahn F, Sierra-Rodriguez J, et al. Anatomical structures in the Leksell pallidotomy target. Stereotact Funct Neurosurg 1998; 70: 32-37.

25. Spiegelmann R, Gofman J. CT-target determination in posteroventral pallidotomy: a universal method. Technical note. Acta
Neurochir 1996; 138: 732-735.

26. Sumanaweera TS, Adler JR, Napel S, et al. Characterization of spatial distortion in magnetic resonance imaging and its implications for stereotactic surgery. Neurosurgery 1994; 35: 696-702.

27. Harris R, Wesbey G. Artifacts in magnetic resonance imaging. In: Kressel HY (Ed). Magnetic Resonance Annual 1988. New York: Raven Press, 1988; 71-112.

28. Alexander E, Kooy HM, van Herk M, et al. Magnetic resonance image-directed stereotactic neurosurgery: use of image fusion with computerized tomography to enhance spatial accuracy. J Neurosurg 1995; 83: 271-276.

29. Lunsford LD. Magnetic resonance imaging stereotactic thalamotomy: report of a case with comparison to computed tomography. Neurosurgery 1988; 23: 363-367. 